\title{
O USO DE SISTEMAS DE INFORMAÇÃO GEOGRÁFICA (SIGs) NA GESTÃO SUSTENTÁVEL DO ASSENTAMENTO JARDIM, BATURITÉ-CE
}

\author{
Lígia Nazaré Aguiar Silva ${ }^{1}$, Adriana Marques Rocha ${ }^{1}$, Evaldo Tavares de Souza Filho $^{2}$, \\ JuAna AngÉlica FElipe FEERnANDES ${ }^{1}$ \\ ${ }^{1}$ Instituto Federal do Ceará (IFCE) \\ ${ }^{2}$ Instituto Nacional de Colonização e Reforma Agrária (INCRA) \\ <ligiaaguiarsilva@gmail.com><adrianamr2@yahoo.com.br> \\ <evaldo_souza@yahoo.com.br><jaff294@hotmail.com> \\ DOI: $10.21439 /$ conexoes.v12i3.1190
}

\begin{abstract}
Resumo. A Política de Reforma Agrária (PRA) foi implementada no intuito de construir um país mais justo e acessível. No entanto, para que esse objetivo seja alcançado é importante a sustentabilidade e independência das pessoas beneficiadas. Diante disso, o objetivo do trabalho é utilizar a ferramenta dos Sistemas de Informação Geográfica (SIG) como um método de avaliação de uso e ocupação do Assentamento Jardim, em Baturité-CE. Para a efetivação deste trabalho foram necessários os seguintes passos: revisão de literatura através de consultas bibliográficas e documentais; visitas à área de estudo com registros de imagens (documentação fotográfica); realização de entrevista semiestruturada no assentamento e identificação/mapeamento dos usos, a partir da experiência em campo e do software QGIS. Constatou-se na pesquisa uma área utilizada essencialmente para subsistência, com cultivo de leguminosas e criação de bovinos e caprinos. Entretanto, essas atividades não fornecem os suprimentos e renda necessários ao sustento dessas famílias. Os assentados possuem ainda vasta área que poderia ser explorada de forma sustentável para melhoria da renda dos mesmos. Com este paradoxo, observa-se a necessidade de outros agentes além da PRA, como projetos socioambientais e assistência técnica para a manutenção das famílias de trabalhadores rurais no campo com qualidade de vida.
\end{abstract}

Palavras-chaves: Geoprocessamento. Análise Ambiental. Planejamento de Uso e Ocupação.

\section{THE USE OF GEOGRAPHIC INFORMATION SISTEMS (GIS) ON THE SUSTAINABLE MANAGEMENT OF JARDIM SETTLEMENT, BATURITÉ-CE}

\begin{abstract}
The agrarian reform policy was implemented in order to build a fairer and more accessible country. However, in order for this objective to be achieved is important the sustainability and independence of the benefited people. In light of this, the objective of this project is to use the tool of Geographic Information Systems (GIS) as an evaluation method of use and occupancy at the Jardim Settlement in Baturité, Ceará. For the realization of this project the following steps were necessary: literature review on the subject from bibliographic and documentary consultation, photographic documentation made during visits to the study area, execution of semi-structured interviews in the Settlement and identification/mapping of the uses from field experience and QGIS software. It was found in the research an area mainly used for subsistence, with leguminous cultivation and cattle and goat farming. However, these activities do not provide the supplies and income needed for the maintenance of these families. The settlers have still vast area that could be explored in a sustainable way to improve their income. With this paradox, is observed the need for other agents in addition to the agrarian reform policy, such as social environmental projects and technical assistance for the maintenance of the rural workers' families in the field with quality of life.
\end{abstract}

Keywords: Geoprocessing. Environmental analysis. Use and Occupancy planning.

\section{INTRODUÇÃO}

A política de reforma agrária realiza inúmeras desapropriações de imóveis rurais em todo o Brasil. Essas áreas, por se localizarem em zonas rurais, regiões que geralmente possuem menor densidade demográfica e maior presença de elementos naturais, exigem maior controle e planejamento quando se refere à ocupação e utilização humana.

A fragilidade dessas áreas e os impactos gerados pela inexistência de planejamento de uso e ocupação adequado exige que sejam adotadas novas metodologias, a fim de minimizar os efeitos negativos gerados 
por assentamentos já criados. Como por exemplo, é possível citar o uso dos Sistemas de Informação Geográfica (SIG) utilizados pelos órgãos ambientais e fundiários, que facilitam e otimizam o trabalho no que tange ao planejamento do uso e delimitação de áreas de restrição legal em assentamentos rurais.

Nessa perspectiva, este estudo objetiva identificar, a partir do uso do SIG, as características ambientais e socioambientais do local cujos questionamentos iniciais são: de que forma o uso dos SIGs auxiliaria na identificação dos usos atuais do Assentamento Jardim? Como poderá contribuir para melhor utilização da área? Como é possível utilizá-lo de forma a manter o assentamento em conformidade com a legislação? O trabalho em tela é um estudo de caso elaborado através de pesquisa de campo, bibliográfica e documental e utilizou especificamente o QGIS como instrumental para elaboração da caracterização socioambiental da área de estudo.

\section{FUNDAMENTAÇÃO TEÓRICA}

\subsection{A Reforma Agrária no Ceará}

A Reforma Agrária é uma política estabelecida em 1964 pelo Estatuto da Terra, definida como "[...] o conjunto de medidas que visem promover melhor distribuição da terra, mediante modificações no regime de sua posse e uso, a fim de atender aos princípios de justiça social e ao aumento de produtividade." (BRASIL 1964).

No Ceará, em condições semelhantes aos demais estados brasileiros, a reforma agrária aconteceu principalmente nos anos de 1980 expandindo-se nos anos de 1990. O processo de redistribuição de terras foi caracterizado por longas ocupações de fazendas e até mesmo, conflitos violentos. "Vários registros demonstram situações de extrema violência, às quais os moradores em luta foram submetidos. Essas violências e arbitrariedades tinham o objetivo de intimidar os camponeses que começavam a se organizar" (ALENCAR; DINIZ, 2010 p. 135).

A partir desses conflitos, houve a consolidação dos movimentos sociais no Ceará, principalmente do Movimento dos Trabalhadores Rurais Sem Terra (MST) e aliado a isso, houve o desenvolvimento da legislação fundiária e os trabalhadores foram tomando conhecimento dos seus direitos, de forma que os protestos isolados tornaram-se mais frequentes e organizados. No mesmo período, foram impostas altas metas de desapropriação ao Instituto Nacional de Colonização e Reforma Agrária (INCRA), combinação de fatores que proporcionou o aumento dos assentamentos nos anos de 1990.

Nesse contexto, muitos assentamentos no Ceará fo- ram criados imediatamente e sem estudo prévio, causando alocação de famílias de forma insustentável e degradando o ambiente. Esses fatores influenciam economicamente as famílias, visto que elas dependem diretamente da disponibilidade dos recursos ambientais, uma vez que "[...] as principais atividades desenvolvidas são a pecuária (bovinocultura, caprinocultura e ovinocultura), a produção de grãos alimentícios (milho e feijão) e matéria-prima (mandioca e algodão) [...]" (QUARESMA; BARRETO, 2002, p. 4).

Entretanto, há muitas áreas já desapropriadas e com grandes potenciais de ocupação que não são utilizadas em sua totalidade, o que comprova a prioridade do governo em obter áreas em detrimento de promover a boa gestão e qualidade dos assentamentos. A consequência desse cenário atual é a incapacidade do INCRA e dos assentados em gerir grandes áreas, visto que o Ceará alcançou grandes índices de desapropriação: no Ceará Estado há 413 assentamentos federais e 39 estaduais que juntos somam 914.371,23 ha (INCRA, 2015) (ver Figura 1).

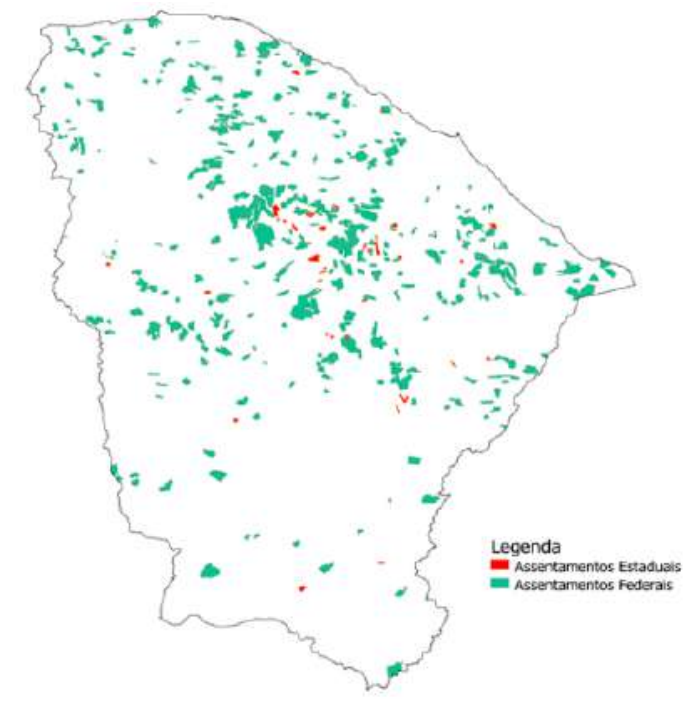

Figura 1: Assentamento no Ceará. Fonte: Adaptado INCRA (2015).

No entanto, para garantir a eficácia da política de reforma agrária, é necessário a implementação de outras políticas públicas e de assistência técnica. Dessa forma, será possível utilizar os recursos naturais da aréa de forma responsável e eficiente, o que resultará na permanência dos assentados no campo.

\subsection{SIG em Assentamentos Rurais}

O uso do SIG nos assentamentos não ocorre de forma interna ou por iniciativa dos assentados. O SIG é utili- 

BATURITÉ-CE

zado como um instrumento de gestão adotado pelo INCRA para auxiliar nas suas competências. Eles podem ser aplicados na mesma área para diferentes objetivos, e devido à confiabilidade e rapidez com que se obtém informações, a tendência é que o INCRA utilize cada vez mais. Em relação à sua função principal de descentralização fundiária Souza Filho et al. (2014 p. 26) comentam que "[...] a geração de mapas mais detalhados, significa maior precisão na avaliação da viabilidade dos imóveis, redução de custos e, consequentemente, maior poder de decisão quanto à continuidade ou não dos processos de obtenção de terras."

No contexto dos assentamentos, o INCRA utiliza essa ferramenta em todo o processo de desapropriação. Inicialmente a atuação dos SIG ocorre durante a identificação e estudo das propriedades auxiliando no estudo de viabilidade para desapropriação, conforme demonstram Thiers e Meireles (2008, p. 53):

\begin{abstract}
Na operação cadastral, levantam-se todas as características gráficas e não-gráficas dos imóveis rurais da área: perímetro (geometria), identificação e qualificação dos detentores dos imóveis, uso atual, aspectos produtivos e tecnológicos de exploração do imóvel, valor das benfeitorias existentes, valor da terra nua e cobertura vegetal em conformidade com os preços de mercado, condição de acessibilidade e qualidade das terras, condição jurídica do imóvel, confrontações e litígios, se esses existirem.
\end{abstract}

Após a obtenção das terras, é dado início ao planejamento do uso e ocupação do solo. No entanto, durante muitos anos, essa fase não existiu, fazendo com que a criação de assentamentos tratasse apenas de desapropriação de terras e alocação as famílias selecionadas. "A pressão dos movimentos sociais para solução dos graves problemas no meio rural e a necessidade do Governo Federal em atingir metas numéricas, têm motivado à implantação de assentamentos sem um planejamento mínimo" (SOARES; ESPINDOLA 2012, p. 113).

Associada à pressão dos movimentos sociais, os estudos acerca dos recursos ambientais e potencialidades agrícolas, durante muitos anos, deixaram de ser realizados por falta de corpo técnico, recursos suficientes e até mesmo pela escassa importância dada aos componentes ambientais. Em consequência disso, hoje há muitos assentamentos com ocupação inadequada, visto que o estudo de capacidade foi realizado em momento posterior ao assentamento das famílias.

O SIG é essencial nos referidos estudos, viabilizando-os, já que são diminuídos os trabalhos em campo e o tempo de elaboração, conforme explica Souza Filho et al. (2014, p. 26): “As vistorias técnicas, dependendo do tamanho e da complexidade dos imóveis rurais, normalmente demandam materiais, deslocamentos - as vezes muito longos - custo e tempo, o que pode tornar o serviço bastante oneroso ou até inviável economicamente".

Atualmente, o INCRA reconhece a necessidade de planejar o espaço de forma a adequar as atividades humanas aos recursos naturais disponíveis. A tendência é que seja realizado todo o planejamento espacial do assentamento, incluindo projetos de infraestrutura necessária, escolas e postos de saúde, estes muitas vezes realizados em parceria com as prefeituras.

No entanto, como consequência da falta de planejamento no passado, existem demandas que surgem de assentamentos já estruturados, principalmente quando se trata da distribuição desigual de terras, o que gera a necessidade do parcelamento da terra, processo que consiste em destinar às famílias todas as áreas do assentamento de forma proporcional.

Ao elaborar o projeto de parcelamento, o INCRA analisa e quantifica todas as áreas: agricultáveis, pedreiras, reserva legal, Áreas de Preservação Permanente (APP). Vale salientar que os trabalhos são realizados de forma participativa, conforme retratado em estudo de caso de Souza Filho et al. (2015).

Os SIG são cada vez mais utilizados na adequação dos assentamentos à legislação ambiental. Na determinação e delimitação da área de reserva legal, são possibilitadas consultas a bancos de dados e imagens de satélites, a fim de auxiliar na escolha da área mais adequada e facilitar a visualização das reservas legais de propriedades vizinhas, viabilizando a criação dos corredores de reserva legal. A identificação de APP também pode ser realizada intermediada pelas geotecnologias, que permitem a partir das curvas de nível identificar topos de morros e encostas que devem ser preservados, bem como delimitar os limites de proteção dos corpos hídricos.

Entretanto, apesar de ser uma ferramenta que traz ganhos ao trabalho desenvolvido pelo Órgão, muitos entraves elementares precisam ser superados. A falta de capacitação dos técnicos para manipulação desses programas e de profissionais suficientes para atender à demanda de trabalho, a precariedade de equipamentos eletrônicos como computadores e a falta de recursos para investir em setores destinados à geração de informações próprias limitam o uso do SIG. Essas condições levam o INCRA a trabalhar em parceria com outros órgãos, sejam federais, estaduais ou municipais, para ter acesso a maior quantidade de dados e arquivos geográficos, na tentativa de complementar o trabalho já realizado internamente. 


\section{MATERIAIS E MÉTODOS}

A área utilizada para o desenvolvimento do estudo foi o Assentamento Jardim localizado no município de Baturité (ver Figura 2), portanto de acordo com Severino (2012, p. 121) trata-se de um estudo de caso: "Pesquisa que se concentra no estudo de um caso particular, considerado representativo de um conjunto de casos análogos".

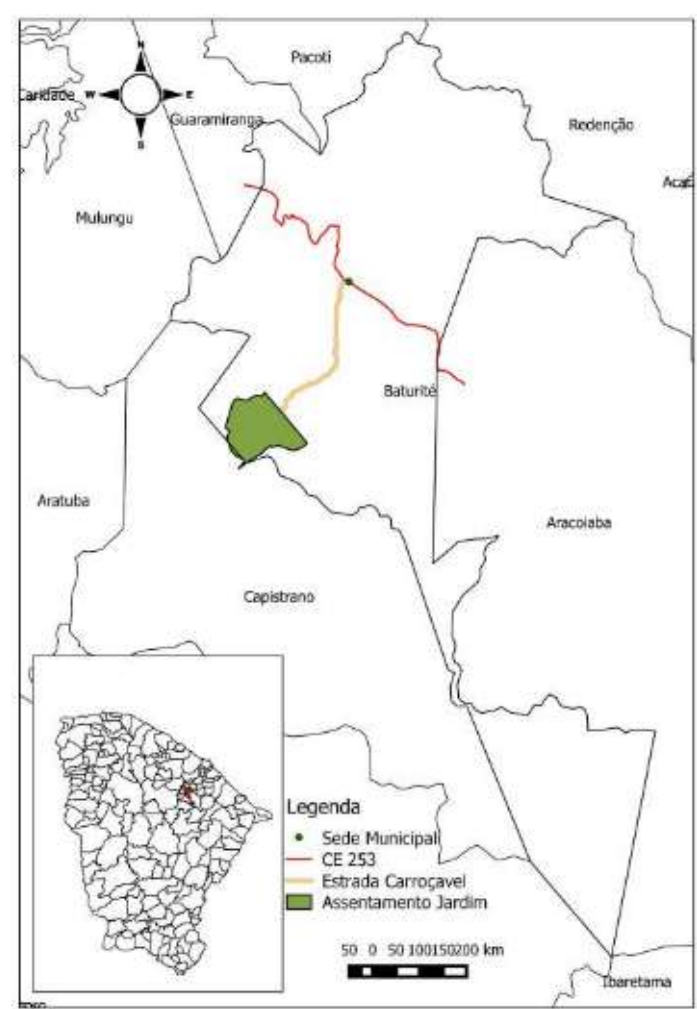

Figura 2: Localização do Projeto de Assentamento Jardim. Fonte: Adaptado, Google (2016).

A coleta de informações ocorreu através de pesquisa bibliográfica e documental, com dados coletados principalmente junto ao INCRA, tais como laudo de vistoria e arquivos shapes da área estudada. A identificação e triagem dos dados obtidos foram elaboradas para que fossem utilizadas como subsídio à pesquisa de campo.

Para a pesquisa de campo, realizou-se uma visita ao Projeto de Assentamento Jardim, no dia 6 de setembro de 2015, para identificação das principais características de uso e ocupação, assim como as atividades econômicas desenvolvidas no local. Todas as informações foram coletadas a partir de conversas com moradores e lideranças da comunidade, através de um questionário semi-estruturado com respostas abertas. Dentre os tópicos abordados, os assentados responderam sobre o processo de organização das famílias: "Como se deu a distribuição de terras dentro do Projeto de Assentamento (PA)?", sobre a presença de muitas áreas de proteção: "O que você acha dos espaços destinados à proteção ambiental presentes no PA?", sobre a realidade econômica de suas famílias: "Recebe/recebeu algum crédito do governo?" e sobre a sustentabilidade do Assentamento "Qual a principal dificuldade para a independência do Assentamento?".

A documentação fotográfica foi elaborada através da câmera Canon T5 com o objetivo de registrar os elementos naturais e a infraestrutura construída na área. A coleta dos pontos de controle se deu pelo equipamento receptor de Global Positioning System (GPS) Garmin Etrex 30, onde foram coletados pontos nas estradas percorridas no assentamento, e nos açudes e áreas de preservação onde foi possível o acesso, a fim de gerar maior segurança e organização as informações apresentadas nos mapas. É válido ressaltar que, apesar da dificuldade de acesso, todas as áreas estão representadas nos resultados através do uso de de imagens de satélite.

\subsection{Elaboração de mapas}

Os mapas foram elaborados com o software livre QGIS versão 2.8 , com a utilização de arquivos shapefile fornecidos pelo INCRA, tais como limite municipal, perímetro do assentamento, estradas e corpos hídricos.

Para a confecção do mapa de declividade adotouse a classificação do Manual de Obtenção de Terras e Perícias Judiciais do INCRA, conforme Quadro 1.

Tabela 1: Classes de declividade do relevo

\begin{tabular}{cc}
\hline Classe de Relevo & $\begin{array}{c}\text { Classe de } \\
\text { Declividade ( \% ) }\end{array}$ \\
\hline Plano & $0-2$ \\
Suave Ondulado & $2-5$ \\
Ondulado & $5-10$ \\
Moderadamente Ondulado & $10-15$ \\
Forte Ondulado & $15-45$ \\
Montanhoso & $45-70$ \\
Escarpado & $>70$ \\
\hline Fonte: INCRA (2006).
\end{tabular}

Inicialmente, foi obtida a imagem Shuttle Radar Topographic Mission (SRTM) com resolução 90 x 90m, para extração das informações de relevo. A imagem foi pós processada para minimização de erros e a partir disso foi possível realizar a classificação de acordo com o Quadro 1 e em seguida, calcular suas respectivas áreas através da ferramenta Calculadora de campo.

No que se refere ao mapa de uso atual, utilizou-se como base o arquivo georreferenciado contendo o perímetro, reserva legal e riacho do assentamento cedido 

BATURITÉ-CE

pelo INCRA-CE. Associado a isso foram lançados os pontos coletados em campo.

O passo seguinte foi a definição das classificações adotadas de acordo com a realidade encontrada em campo: estradas, rios, agrovila, açudes, sede, APPs, reserva legal, áreas exploradas, seja por agricultura ou criação de animais, e áreas sem uso, aquelas em que os assentados não desenvolvem nenhuma atividade. Em seguida, os usos identificados foram vetorizados e classificados em uma das referidas categorias.

\section{RESULTADOS E DISCUSSÕES}

\subsection{Localização do Assentamento Jardim}

O assentamento federal Jardim é um dos 4 assentamentos situados em Baturité, criado no ano 2000, e em uma área de 763 ha atende a 30 famílias, número máximo permitido pelo estudo de capacidade do assentamento. O local está situado a $14 \mathrm{~km}$ da sede do município e tem como principal acesso a estrada Raposo Oiticica. No entorno existem grandes propriedades, que também possuem áreas verdes (ver Figura 3) o que torna ainda mais relevante a conservação da área para que não haja alterações no microclima e nos ecossistemas locais.

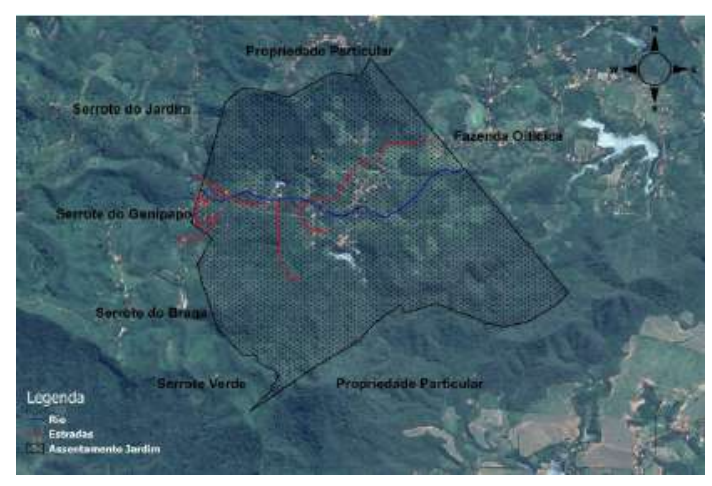

Figura 3: Área de entorno do assentamento Fonte: INCRA, adaptado (2016).

\subsection{O processo de conquista da terra}

A reivindicação pela área que hoje corresponde ao assentamento começou onze anos antes de sua criação, em 1989. A demanda pela desapropriação da Fazenda Jardim surgiu das famílias rendeiras que moravam na propriedade e estavam insatisfeitas com as rígidas e precárias condições de trabalho às quais eram submetidas. Assim, depois de muitos desacordos entre os empregados e o proprietário, em 1997, o Sindicato dos Trabalhadores Rurais de Baturité foi procurado, e por intermédio dele, a demanda chegou ao INCRA para que fosse estudada a viabilidade da desapropriação (INCRA, 1999).

Em julho de 1999, foi realizada a vistoria que viabilizou a desapropriação. Na ocasião foi realizado o levantamento da área com uso de GPS e analisados os aspectos ambientais a partir da classificação do relevo, solos e vegetação, uso atual da terra assim como o levantamento das benfeitorias. A conclusão do estudo mostrou que se tratava de uma grande propriedade improdutiva e, portanto, passível de desapropriação (INCRA, 1999). Dessa forma, o Assentamento Jardim foi criado no ano seguinte.

Um fato interessante nesse processo é que, no laudo de vistoria constava que o imóvel poderia assentar vinte famílias, no entanto, no mês de agosto de 1999 houve a retificação para quarenta famílias e, em outubro do mesmo ano, voltou a vinte famílias. Isso possivelmente se deve à pressão sofrida pelo INCRA para cumprir as elevadas metas anuais de famílias assentadas. Por fim, $o$ assentamento foi limitado definitivamente a trinta famílias, à margem do que o laudo técnico propôs. Isso permitiu a todas as 16 famílias que ainda moravam na propriedade permanecer, e ocorrer a inclusão de outras de comunidades vizinhas (INCRA, 1999).

\subsection{Aspectos Ambientais}

Os diagnósticos ambientais, de uma maneira geral, eram realizados com pouca precisão e confiabilidade. Portanto, as conclusões obtidas nesses diagnósticos são resultados de observações e da intensa experiência de campo dos técnicos do INCRA. Em análise técnicoagronômica realizada pelo INCRA para desapropriação foram observadas espécies de flora características da caatinga: marmeleiro-branco (Croton sincorensisMart), jurema-preta (Mimosa nigra-Hub), sabiá (Mimosa caesalpinifolia-Benth), angico (Anandenanthera macroparca), aroeira (Astronium urundeuva-Engl), catingueira (Caesalpinia pyramidalis). Durante a visita de campo foram identificadas espécies como ipê roxo (Tabebuia impetiginosa- Mart.) (ver Figura 4), arapiraca (Anadenanthera peregrina), juazeiro (Ziziphus joazeiro) (ver Figura 5).

A maior porção de terra possui relevo forte ondulado e para a agricultura é um fator limitante por dificultar o acesso humano e uso de máquinas agrícolas (ver Figura 6). Entretanto, um fator fundamental à boa produção ocorre em abundância no assentamento: a água. $\mathrm{O}$ assentamento dispõe de seis açudes, um deles com capacidade para dois anos de armazenamento (ver Figura 7). Essa é uma característica prioritária a ser considerada no assentamento, pois proporciona a segurança hídrica aos homens e viabiliza as atividades agrícolas, 


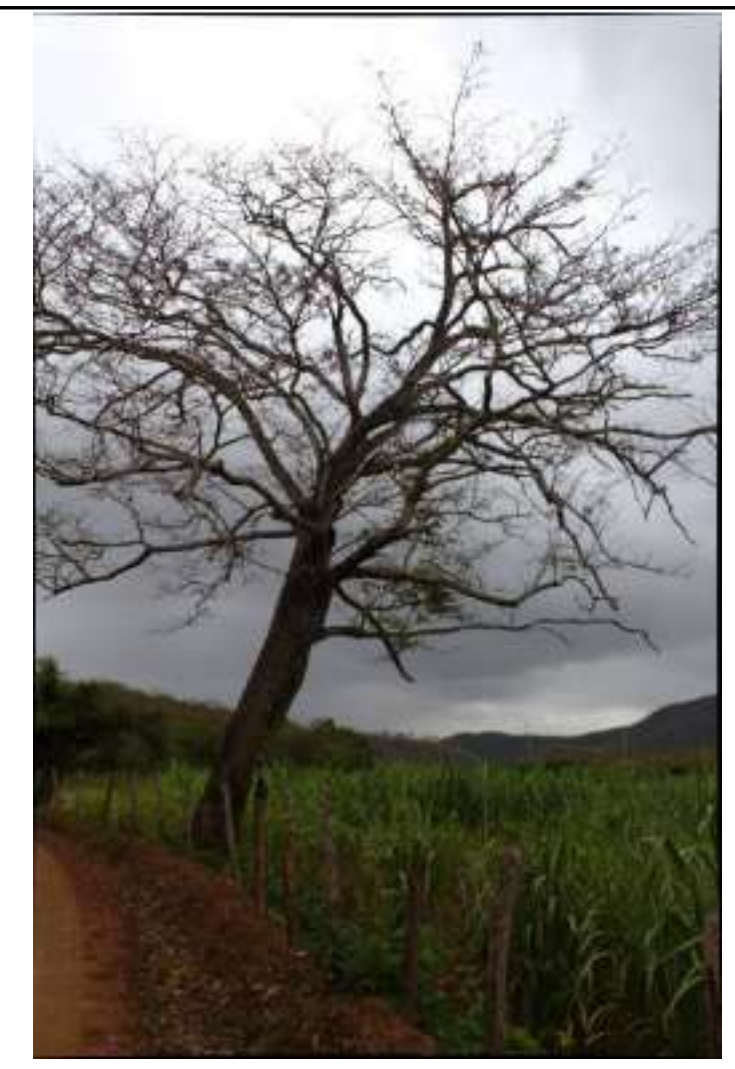

Figura 4: Ipê roxo

Fonte: Elaborada pelos autores.

fornecendo aos assentados a piscicultura como alternativa econômica (INCRA, 1999).

O solo é importante componente no estudo de uma área rural. No assentamento jardim foram identificados: Luvissolo Crômico, Neossolo Flúvico, Neossolo Litólico e Planossolo Háplico (INCRA, 1999).

\subsection{Mapeamento do Assentamento Jardim}

A classificação de relevo do assentamento foi realizada ainda com base em simples observações de campo (QUADRO 1), tornando-a pouco precisa quando comparada às realizadas através do SIG, conforme quadro 2 .

O mapa de declividade apresentou divergências entre o quadro de área elaborado durante vistoria e o elaborado a partir do SIG (QUADRO 3).

A análise do quadro 3 denota que a classe predominante na área é a de relevo forte ondulado, com área correspondente a 357,40 ha. Observa-se ainda a presença da classe moderadamente ondulada, inexistente na classificação do quadro 2 .

Os resultados obtidos na pesquisa e demonstrados

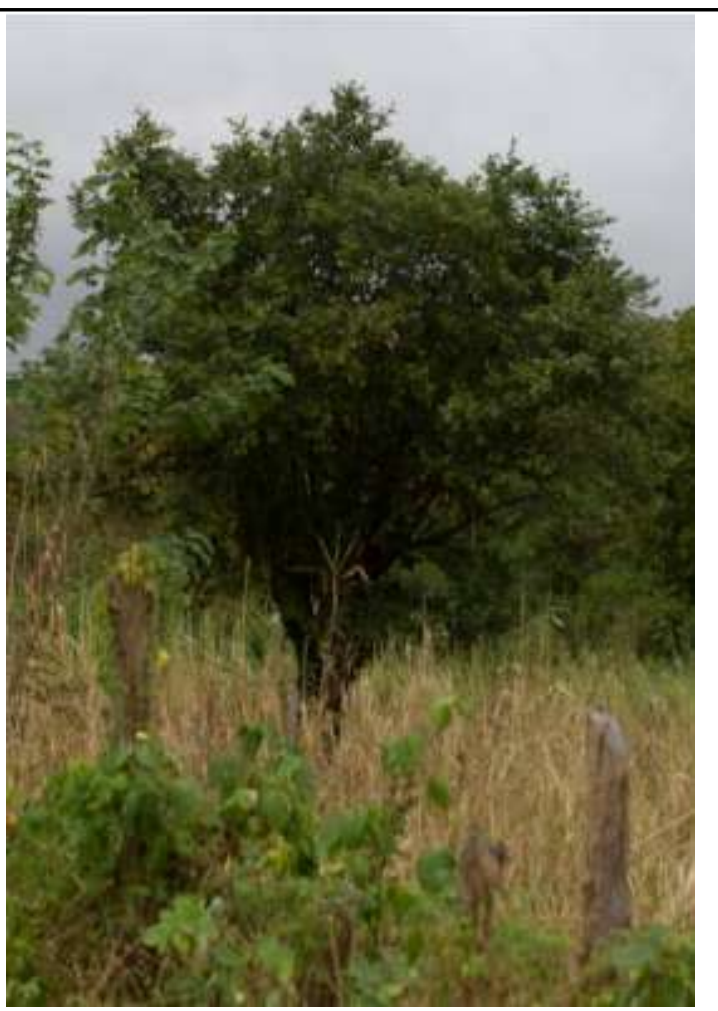

Figura 5: Juazeiro

Fonte: Elaborada pelos autores.

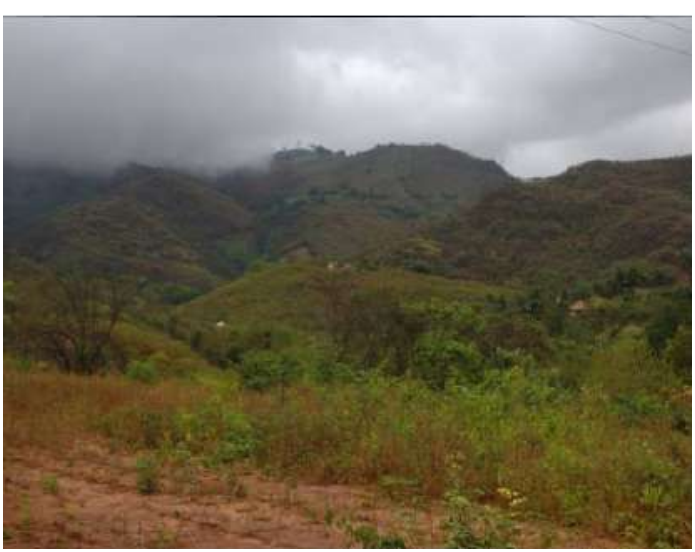

Figura 6: Relevo do assentamento

Fonte: Elaborada pelos autores.

no quadro 3 foram espacializados no mapa de declividade do Assentamento Jardim (ver Figura 8).

O uso da área na atualidade é feito baseado na divisão ocorrida durante a locação das famílias. Entre os principais usos estão: criação caseira de bovinos, caprinos (ver Figura 10) e ovinos, além dos cultivos de milho (ver Figura 9), feijão e banana, produtos que servem para o consumo próprio e comercialização nos municí- 


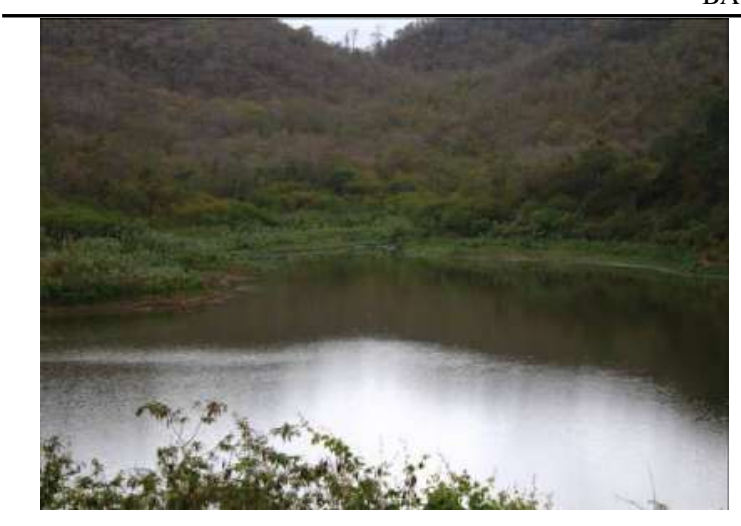

Figura 7: Açude Coati

Fonte: Elaborada pelos autores.

Tabela 2: Classificação do relevo

\begin{tabular}{ccc}
\hline RELEVO & $\begin{array}{c}\text { PORCENTAGEM } \\
(\boldsymbol{\%})\end{array}$ & $\begin{array}{c}\text { AREA } \\
(\mathbf{h a})\end{array}$ \\
\hline Plano & 5,00 & 38,17 \\
Suave Ondulado & 20,00 & 152,7 \\
Ondulado & 40,00 & 305,4 \\
Forte Ondulado & 20,00 & 152,7 \\
Montanhoso & 15,00 & 114,52 \\
\hline
\end{tabular}

Fonte: INCRA (1999).

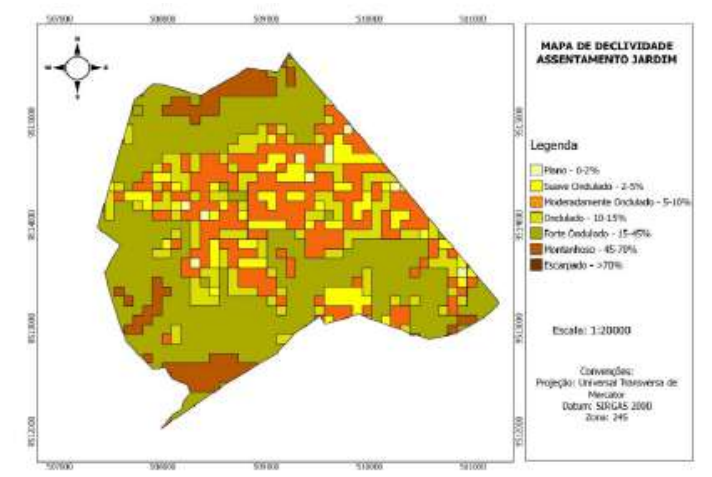

Figura 8: Mapa de declividade do assentamento Jardim. Fonte: Elaborada pelos autores.

pios e comunidades do entorno.

Cada grupo familiar possui 10 hectares (ha), no entanto os assentados relataram utilizar somente até a metade dessa parcela, deixando preservados os hectares remanescentes. Eles atribuem isso ao fato de que a utilização total da área seria inviável por ser muito onerosa. Além disso, o relevo dificulta o acesso e não contribui para seu uso integral, resultando em uma grande parcela do assentamento sem qualquer utilização.

O mapa de declividade e de uso revela a influência do relevo no processo de uso e ocupação do imóvel,

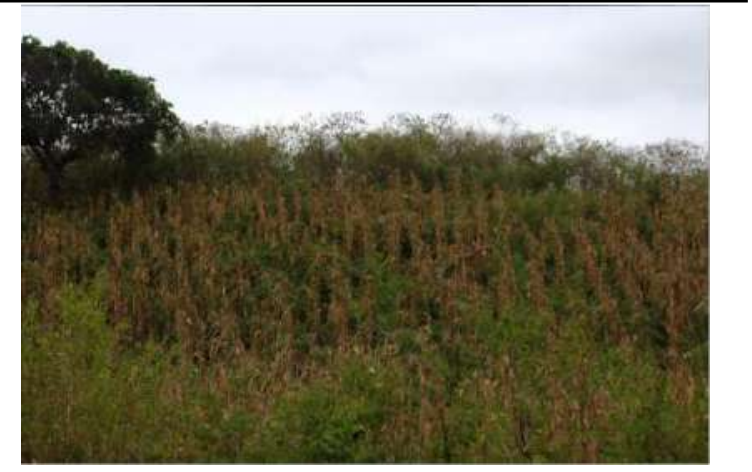

Figura 9: Plantação de milho Fonte: Elaborada pelos autores.

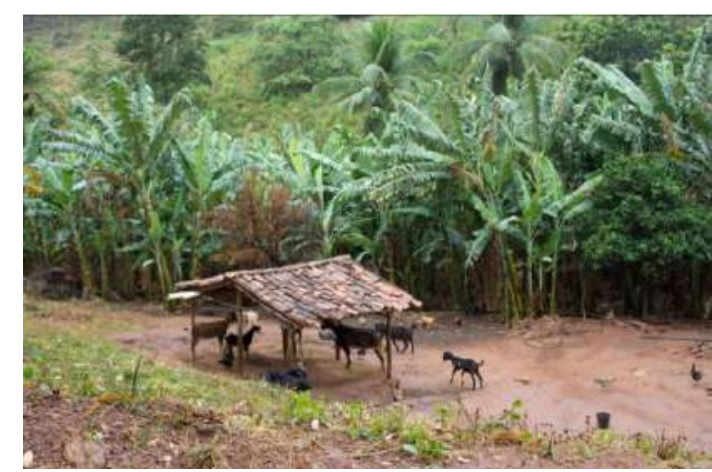

Figura 10: Criação de caprinos Fonte: Elaborada pelos autores.

uma vez que a maior parte das áreas exploradas e áreas residenciais estão em locais onde o relevo varia de plano a moderadamente ondulado.

No cálculo foram consideradas áreas exploradas as que possuem cultivos agrícolas, criação de animais e as que estão desprovidas de cobertura vegetal, o que indica que possivelmente ocorreu uso recente do local, uma vez que em visita de campo não foram identificadas áreas abertas por queimadas ou outros fatores externos.

No Quadro 4 verifica-se que as áreas exploradas não chegam a 60 ha, demonstrando que não são utilizados sequer metade dos 10 ha destinados a cada família. Ainda no Quadro 4 observa-se sobreposição de áreas, pois o Açude Coati está inserido na reserva legal e existem áreas exploradas dentro de APPs. Devido a esse fato a soma das áreas não representa o total da área do assentamento.

A infraestrutura foi pouco modificada uma vez que a sede, que compreende associação dos agricultores (ver Figura 11) e local destinado a reuniões e armazenamento de equipamentos coletivos (ver Figura 12), já existiam, assim como uma parcela das casas, pois mui- 

BATURITÉ-CE

Tabela 3: Classificação do relevo utilizando SIG

\begin{tabular}{ccc}
\hline RELEVO & PORCENTAGEM (\%) & AREA (ha) \\
\hline Plano & 1,11 & 8,49 \\
Suave Ondulado & 8,95 & 68,34 \\
Ondulado & 21,90 & 167,21 \\
Moderadamente Ondulado & 13,80 & 105,35 \\
Forte Ondulado & 46,81 & 357,4 \\
Montanhoso & 7,43 & 56,7 \\
Escarpado & 0,00 & 0 \\
\hline
\end{tabular}

Tabela 4: Uso atual das terras do assentamento

\begin{tabular}{ccc}
\hline USO & PORCENTAGEM (\%) & ÁREA (ha) \\
\hline Açudes & 1,43 & 10,95 \\
Áreas exploradas & 7,84 & 59,87 \\
Áreas de Preservação Permanente & 4,13 & 31,55 \\
Áreas Construídas (sede e residências) & 0,67 & 5,18 \\
Área não explorada & 61,96 & 473,13 \\
Reserva Legal & 24,88 & 190,03 \\
\hline TOTAL & $\mathbf{1 0 0}$ & $\mathbf{7 7 0 . 7 1}$ \\
\hline
\end{tabular}

tas famílias já moravam ali enquanto área privada.

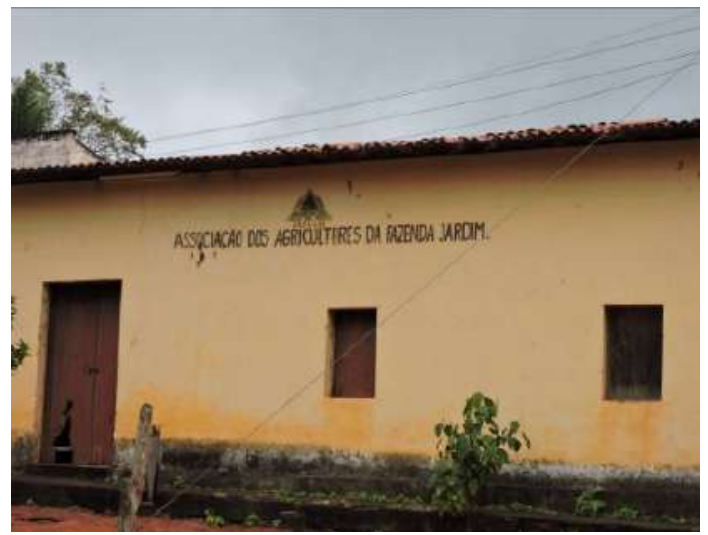

Figura 11: Associação dos agricultores Fonte: Elaborada pelos autores.

A reserva legal foi delimitada em uma área de difícil acesso e não utilizada, no entanto os entrevistados demonstraram conhecimento da restrição de uso na área, diferentemente das APPs, as quais eles sabem da restrição, porém foram encontrados pontos de queima de lixo (ver Figura 13) e cultivos próximos a açudes.

No mapa de uso (ver Figura 14) há grande quantidade de área ociosa, demonstrando potencial não explorado pelos assentados, uma possível consequência da falta de assistência técnica e projetos que os auxiliem a fazer o uso viável da área. Essa versão é confirmada pelo assentado Entrevistado A, quando questionado so-

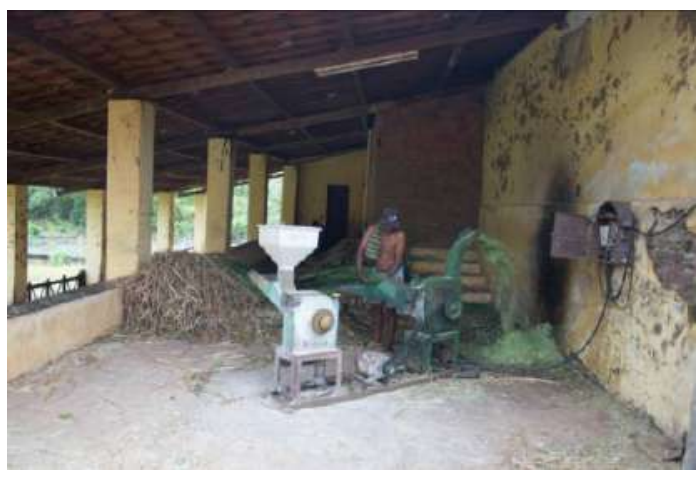

Figura 12: Assentado trabalhando na sede do PA Fonte: Elaborada pelos autores.

bre a principal dificuldade para viver no assentamento:

\begin{abstract}
Eu penso que dificuldade começa na falta de conhecimento dos agricultores, e segundo, 'os governo' que sabe que os agricultores não são pessoas 'formada' ai 'bota' os trabalhadores dentro de um assentamento desse e tchau, nos 'tamo' aqui já vai fazer 4 anos que nós não temos assistência técnica e pra nós 'conseguir' um projeto é muito difícil (Entrevistado A, 2015).
\end{abstract}

O ponto de vista do entrevistado é relevante quando responde ao questionamento sobre o que poderia melhorar no assentamento, pois ele ressalta a transformação dos assentamentos em favelas rurais, devido ao incipiente acompanhamento dado às famílias após serem assentadas. 

BATURITE-CE

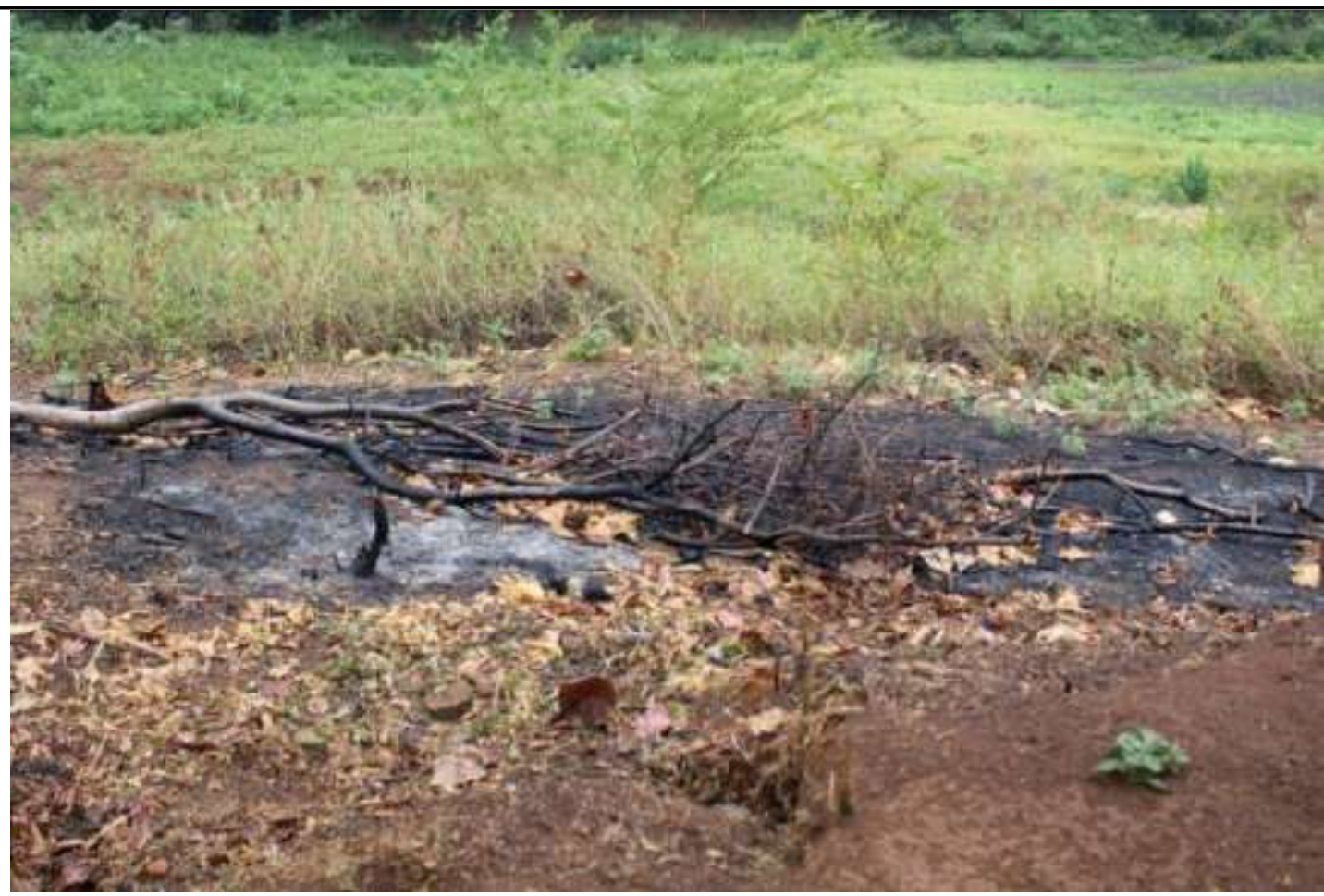

Figura 13: Pontos de queimadas em APP Fonte: Elaborada pelos autores.

Era pra ter uma avaliação e ver de que forma o trabalhador 'tá" vivendo, ele ta usufruindo desse patrimônio porque isso aqui é um patrimônio que foi comprado com os impostos que não são só dos agricultores, é imposto meu, seu e de todos os brasileiros 'ne'? E é tão bom quando a gente vê o imposto da gente bem empregado 'ai' todo mundo fica satisfeito mas infelizmente o governo 'bota' a gente aqui ai vira favela rural porque na realidade o governo não tem o compromisso de ajudar 'nós' (Entrevistado A, 2015).

Além da dificuldade em utilizar todos os hectares destinados às famílias, os assentados revelam problemas para gerir as áreas mais distantes dos núcleos residenciais, facilitando a invasão por outras pessoas e a retirada de elementos naturais do assentamento.

Nosso terreno tem uma extrema com a Oiticica que tem muita madeira de obra sabe? E o povo 'tão' roubando a madeira, fizeram um desmatamento do tamanho do mundo, nós 'vamo' lá pra ver mas nunca acha ninguém, não sei se de noite ou domingo, só sei que ele vem e tira tranquilo porque é longe demais, nós não escuta nada (Entrevistado B, 2015).

Associada à problemática constatada, outro aspecto que poderia justificar o uso incipiente da área foi abordado pelo entrevistado $\mathrm{C}$, um dos primeiros moradores do assentamento:

\begin{abstract}
Eu considero essa área que nos 'mora' aqui como uma bola de ouro, o que falta é conhecimento, é técnico que venha trazer o seu conhecimento lá de fora pra cá pra junto dos trabalhadores e os trabalhadores 'querer' também 'né' porque as vezes a gente recebe uma coisa e muitos aqui dizem que não 'quer' aí não adianta' (Entrevistado C, 2015).
\end{abstract}

De acordo com os relatos coletados, houve muitas tentativas de aproveitamento da área disponível a fim de proporcionar maior empoderamento econômico com a implantação de piscicultura e apicultura. No entanto, devido à falta de conhecimento dos assentados para gerir estas atividades, e ao rompimento da parede do açude, a desistência se deu rapidamente.

Os aspectos mencionados podem ser visualizados no Mapa 2, onde está espacializada a ociosidade das áreas, as áreas exploradas caracterizadas por cultivos agrícolas e criação animal e demais usos, o que demonstra o potencial de terra a ser explorada.

\section{CONCLUSÕES}

O uso dos SIGs no mapeamento dos imóveis rurais fornecem informações sobre o meio físico, ajudam a compreender os usos atuais e podem embasar o planejamento do uso, pois é possível consultar e analisar de forma prática as particularidades de cada local. 

BATURITÉ-CE

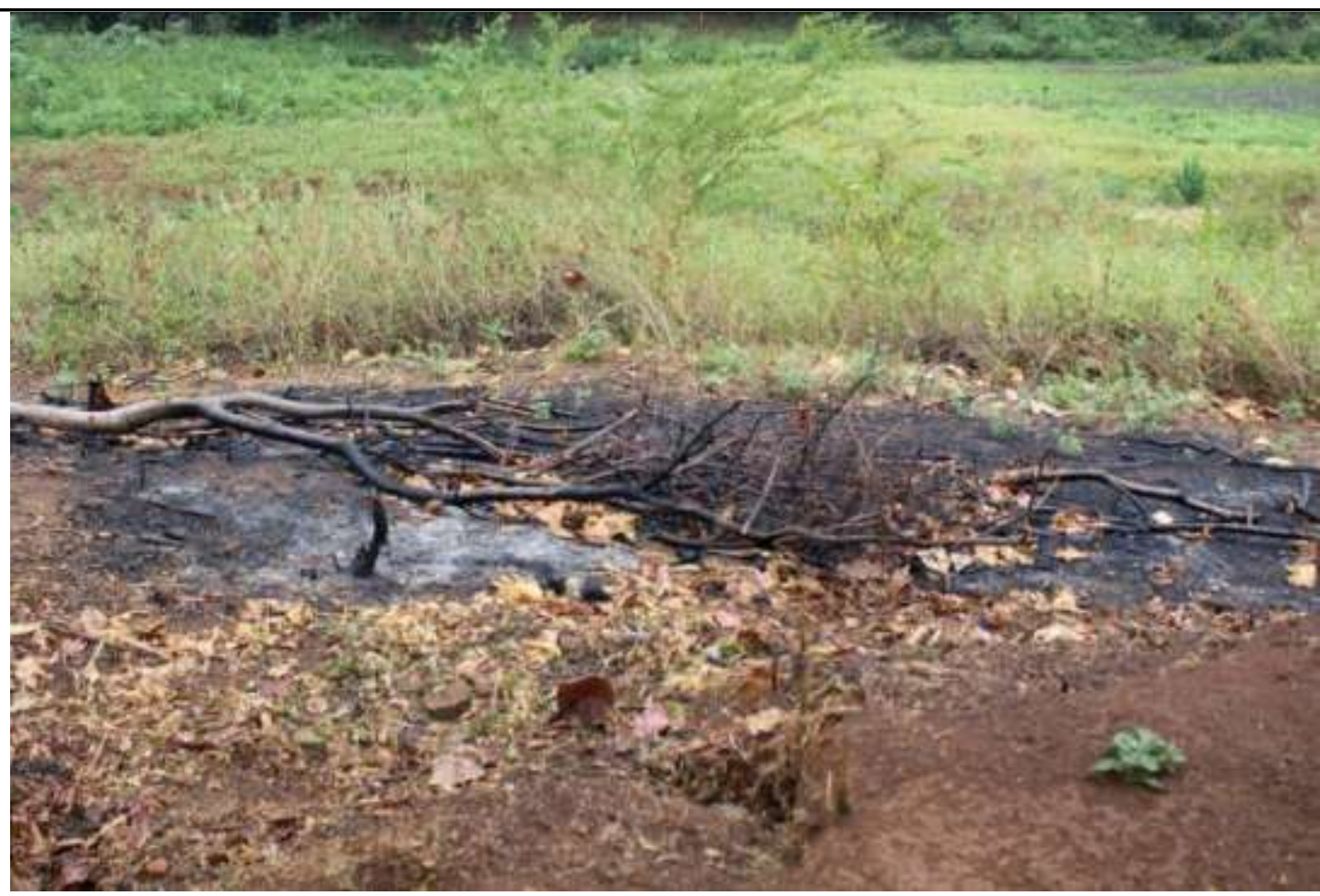

Figura 14: Uso Atual do Assentamento Jardim Fonte: Elaborada pelos autores.

Diante das informações coletadas por meio do QGIS e imagens do software da Google, Google Earth versão 7.1 , constata-se que a maior parte da área de estudo está situada em um local com relevo bastante ondulado e é formada por grandes coberturas vegetais, que são intercaladas por áreas destinadas à agricultura e criação de animais.

O assentamento Jardim fornece condições adequadas de subsistência aos assentados, apesar de possuir áreas subutilizadas. As famílias desenvolvem diferentes atividades no campo, que poderiam ser potencializadas para incremento da renda dos assentados.

Entretanto, ainda existe a dependência dos benefícios sociais. Isso demonstra a importância e necessidade do incentivo a políticas públicas que levem ao trabalhador rural assistência técnica e investimentos em tecnologias e práticas que estimulem o empreendedorismo e sua permanência no campo.

Conclui-se com este estudo que a gestão sustentável de um assentamento rural necessita de dois pilares: os estudos de identificação dos seus aspectos ambientais, aspectos estes que permitam conhecer o nível de ocupação que a área está apta a receber, fazendo com que seu planejamento de uso seja feito de forma adequada e participativa, e por fim, o acompanhamento e aprimo- ramento das atividades desenvolvidas em campo, permitindo que seja explorado todo o potencial da área, gerando renda e garantindo que essas atividades sejam realizadas de forma sustentável.

$\mathrm{O}$ artigo em tela não esgota o assunto, pois observase a necessidade de análise dos aspectos de uso e ocupação também no período seco, uma vez que o trabalho de campo ocorreu em período chuvoso, e esse fato pode, possivelmente, inibir algumas peculiaridades do local.

\section{REFERÊNCIAS}

ALENCAR, F. A. G. d.; DINIZ, A. S. Mst-ceará, 20 anos de marchas. Mercator-Revista de Geografia da UFC, Universidade Federal do Ceará, v. 9, n. 20, p. 133-148, 2010.

BRASIL. Lei no 4.504, de 30 de novembro de 1964. 1964. Disponível em: <http://www.planalto.gov.br/ ccivil_03/leis/14504.htm> Acesso em: 08 abr 2015.

GOOGLE. Google Earth. Versão 7.1. Imagens

do Município de Baturité. 2016. Disponível em: $<$ https://www.google.com.br/earth/download/gep/ agree.html> Acesso em: 5 mar 2016. 
INCRA. Laudo de vistoria imóvel: "Fazenda Jardim” Município: Baturité - Ceará. Baturité, 1999.

Manual de obtenção de terras e perícias judiciais. 2006. Disponível em: <http://www.incra. gov.br/sites/default/files/uploads/servicos/publicacoes/ manuais-e-procedimentos/manual_de_obtencao.pdf> Acesso em: 12 jan 2016.

Plano de ação ambiental. Brasília: [s.n.], 2008. Disponível em: <http://www.incra.gov.br/sites/default/ files/plano_acao_ambiental_v11dez2008.pdf> Acesso em: 24 nov 2015.

Situação-plano de manejo florestal SR (02). [S.l.], 2014.

Tipos de projetos criados e o número de famílias assentadas nos projetos de reforma agrária. [S.1.], 2015.

QUARESMA, C. L.; BARRETO, R. C. S. A reforma agrária como estratégia de desenvolvimento do Ceará: um estudo de caso. 2002. Disponível em: <http://www.sober.org.br/palestra/12/11P494.pdf>. Acesso em: 3 mar 2015.

SEVERINO, A. J. Metodologia do trabalho científico. 23. ed. São Paulo: Cortez Editora, 2012. P. 121.

SOARES, J. L. N.; ESPINDOLA, C. R. Geotecnologias no planejamento de assentamentos rurais: premissa para o desenvolvimento rural sustentável. REVISTA NERA, v. 1, n. 12, p. 108-116, 2012.

Souza Filho, E. T. S.; SILVA, L. N. A.; FEITOSA, C. L.; ROCHA, G. B. Mapeamento digital de solos. para quê? para quem? Boletim Sociedade Brasileira de Ciência do Solo, v. 39, n. 1, p. 1, Julho 2014.

. Uso do solo e organização espacial no projeto de assentamento recreio, quixeramobim/ce. In:

Congresso Brasileiro de Ciência Do Solo. Natal: [s.n.], 2015. Disponível em: <http://eventosolos.org.br/ cbcs2015/arearestrita/arquivos/297.pdf>. Acesso em: 16 out 2015 .

THIERS, P.; MEIRELES, A. J. A. d. Geotecnologias aplicadas à reestruturação fundiária. Boletim Goiano de Geografia, v. 26, n. 2, p. 47-60, julho 2008. Disponível em: <http://cascavel.ufsm.br/revistas/ ojs-2.2.2/index.php/extensaorural/article/view/5590> Acesso em: 9 mar 2016. 